\title{
Having fun with van - a Nanosyntactic take on syncretism
}

\author{
Erin Pretorius \\ Department of General Linguistics, Stellenbosch University, South Africa \\ E-mail: erink@sun.ac.za
}

\begin{abstract}
Syncretism is the phenomenon where one (phonological) form is able to spell out more than one (grammatical) function. The $\mathrm{P}$ (repositional) element van ("from/of") in Afrikaans represents an instance of syncretism: it is able to spell out many different functions including spatial, possessive and partitive functions. Any theoretical framework seeking to account for how form relates to function ought to provide an account of this phenomenon. Within the broad minimalist approach, Nanosyntax (NS) has yielded the most systematic and explicit accounts of syncretism (cf. e.g. Starke 2009; Caha 2007, 2009). This paper offers a nanosyntactic characterisation of the Afrikaans P element van, focusing specifically on its behaviour in Afrikaans partitive constructions and offering a tentative analysis to account for the seemingly irregular behaviour displayed by van in these constructions. The analysis is based on a modified syntactic decomposition of "the genitive zone" proposed by Caha (2009). The presence of an additional node, Specific (SPF), is argued for in the lowest layer of the structure that is encoded on the lexical entry for van. One merit of the proposed analysis is that it takes into account how van interacts with other word-level elements in the phrase.
\end{abstract}

Keywords: partitive, pseudo-partitive, Afrikaans, syncretism, nanosyntax

\section{Introduction}

Syncretism, in general terms, refers to the phenomenon where one phonological form is able to spell out more than one grammatical "meaning" or function. The phenomenon has been investigated from a wide variety of linguistic approaches, including unification-based grammars, ${ }^{1}$ Network Morphology ${ }^{2}$ and Paradigm Function Morphology. ${ }^{3}$ As far as could be ascertained, the phenomenon has not received systematic attention within the broad minimalist approach to grammatical inquiry. Within this approach, Nanosyntax (NS) represents the

\footnotetext{
${ }^{1}$ Such approaches include Generalised Phrase Structure Grammar (GPSG; cf. Gazdar et al. 1985), Head-Driven Phrase Structure Grammar (HPSG; cf. Pollard and Sag 1994), Functional Unification Grammar (FUG; cf. Kay 1979) and Lexical Functional Grammar (LFG; cf. Kaplan and Bresnan 1982).

${ }^{2}$ Cf. e.g. Baerman et al. (2005) and Brown and Hippisley (2012).

${ }^{3}$ Cf. e.g. Stump $(1993,2001)$ and Sadler and Nordlinger (2006).
} 
framework that has yielded the most explicit accounts of syncretism (cf. e.g. Starke 2009; Caha 2006, 2009). This paper offers a characterisation of syncretism from an NS point of view. The paper investigates the Afrikaans P element van ("from/of") and how a structural analysis of the syncretism shown by this element could assist in accounting for some (seemingly) irregular behaviour.

This paper focuses specifically on providing a structural account of van when it is spelling out a pseudo-partitive function, such as in (1a); the analysis will be extended to the other partitive functions represented in (1b) and (1c) as well. The data in (1d-i) illustrate other functions which van regularly spells out and, although this paper does not attempt analyses of these other functions, a full NS account of the syncretism shown by this P element should include these functions as well.
(a) 'n Sny (* ${ }^{*}$ van $)$ koek a slice of cake "A slice of cake"

(b) (Party) van sy vriende some of his friends "Some of his friends"

(c) 'n Man van staal

a man of steel

"A man made of steel"

(d) 'n Pelgrim van ver

a pilgrim from far

"A pilgrim from afar"

(e) 'n Entjie $\quad \underline{\text { van }}$ die kroeg (af)

a distance.DIM from the pub (of)

"A short distance from the pub"

(f)

Kamers van derdejaarstudente

rooms of third-year students

"Rooms of third-year students"

(g) Sy hou van klein kinders she likes of small children

"She likes small children"

(h) 'n Juweel van 'n dorpie

a jewel of a town.DIM

"A jewel of a little town"
- Pseudo-partitive

(Corver 1998; 2004)

- "Typical” partitive

- "Made of"-partitive

- Locative

- Path

- Possessive

- Verbal particle

- Comparative QBNP4

(Den Dikken 2006)

\footnotetext{
${ }^{4}$ QBNP stands for "qualitative binomial noun phrase" - a nominal expression in which the qualities of one NP are either compared (comparative QBNP) or attributed (attributive QBNP) to another NP.
} 
An important distinction concerns the difference between syntactic case, which relates to function, and morphological case, which relates to form. The need for this distinction arises from the fact that various functions can be associated with any given (morphological) case form. For example, "possessor" is a function often associated with the genitive morphological case form (Caha 2009:110-120). Caha's solution for this mismatch is to provide a finer decomposition for his case hierarchy, as in the following: Nominative $<$ Accusative $<$ Genitive $<$ Dative $<$ Instrumental $<$ Comitative. In other words, he identifies a set of consecutive nodes which are normally associated with a single morphological case, such as the genitive form. All the nodes cumulatively corresponding with the genitive form, then, are collectively referred to as the "genitive zone". This explains how it is possible for one morphological case to have various (grammatical) functions: each head in the genitive zone cumulatively corresponds with a different function while receiving the same morphological spellout (Caha 2009:112-125). Caha proposes that the genitive zone comprises four heads, namely PREPOSITIONAL $\left(=\mathrm{LOC}_{2}\right)$, PARTITIVE (PART), POSSESSIVE (POSS) and LOCATIVE $\left(\mathrm{LOC}_{1}\right)$. The heads are organised as follows:

$$
\text { Dative zone }>\underbrace{\text { LOC2 }>\text { PART }>\text { POSS }>\text { LOC }_{1}}_{\text {Genitive zone }}>\text { Accusative zone }
$$

In Afrikaans, the $\mathrm{P}$ element that is typically associated with the genitive zone of Caha's decomposition is van. A systematic investigation of van with regards to (2) should address two main questions: (i) Can van be said to fulfil all the functions outlined in (2)?, and (ii) can van also spell out information which is not captured by (2)? Note that an exhaustive investigation of all the functions of van falls outside the scope of this paper, which focuses on the partitive function. Note, in addition, that $\mathrm{LOC}_{2}$ of Caha's decomposition is omitted from the present study because it does not seem to be associated with $v^{5} n^{5}$; this issue remains a topic for further investigation. The decomposition assumed here, therefore, is the one represented in (3).

\footnotetext{
${ }^{5}$ The type of information which is spelled out by $\mathrm{LOC}_{1}$ and $\mathrm{LOC}_{2}$ in (2) is commonly described as spatial (as opposed to, for instance, grammatical). Spatial elements "map out" the relationship between two nominal expressions (DPs), a figure and a ground, placing the figure within some spatial relation to the ground. The functions $\mathrm{LOC}_{1}$ and $\mathrm{LOC}_{2}$ in (2) are both associated with place (a non-directional point in space). The difference between these functions does not concern the nature of the relationship between figure and ground (which has to do with the difference between place and path); instead, it concerns the nature of the ground. With $\mathrm{LOC}_{1}$, the ground takes the form of an abstract, one-dimensional point in space that does not take on a shape; with $\mathrm{LOC}_{2}$, the ground takes the form of a two- or three-dimensional object in space which interacts in a more tangible way with the figure. The difference can be made concrete by comparing "at/near" with "in/on": both pairs denote merely a location, however "in/on" presupposes a surface or an interior of the ground, whereas "at/near" does not (cf. Caha 2009:126). The data in (i) below correspond with an abstract, one-dimensional location in space, and no information regarding the spatial dimensions of the ground ("ver/hier") is available.

(i) (a) 'n Pelgrim van ver a pilgrim from far

(b) 'n Man van hier a man from here
} 


\author{
Dative zone $>\underbrace{\mathrm{PART}>\mathrm{POSS}>\mathrm{LOC}_{1}}>$ Accusative zone \\ Genitive zone
}

Sections 1.1 and 1.2 sketch brief outlines of the NS framework and syncretism respectively; section 1.3 locates syncretism within the NS framework, providing more information about how this phenomenon is accounted for within NS. Section 2 describes the partitive functions of van. Section 3.1 proposes a tentative analysis of van in the pseudo-partitive construction in Afrikaans; this analysis is extended to the typical and the "made of"-partitive constructions in section 3.2. Section 3.3 discusses some limitations of the proposed analysis and, finally, the findings are summarised in the concluding section 4.

\title{
1.1 The Nanosyntactic framework
}

NS takes the mental grammar to be organised in such a way that the syntactic component precedes the lexicon proper. This means that syntactic structure passes from the syntactic component into the lexicon proper, where it is used as a template for the insertion of lexical items. The "ingredients" of syntax are primitive, sub-morphemic features which are drawn from a universal repository and are sometimes referred to as "syntactico-semantic features". ${ }^{6}$ The fact that these features are sub-morphemic means that linguistic elements must match with "chunks" of structure from the syntax - each lexical item spells out a whole sequence of nodes. The spellout of non-terminal nodes in the syntactic tree is thus a crucial device within the framework and forms the basis of the nanosyntactic account of syncretism. ${ }^{7}$

In order for lexical items to be inserted into the syntactic structure, they must themselves be encoded with a structure which can be used to identify a match. Lexical items thus comprise phonological form, semantic information and syntactic structure. Nanosyntacticians are therefore concerned not only with developing an account of the syntactic structure which enters the lexicon, but also with identifying the structures encoded on lexical items. Spellout - the process by which syntactic structure is matched to the structures encoded on lexical items which

One could argue, on the basis of (i) and the impossibility of van to spell out $\mathrm{LOC}_{2}$, that a $\mathrm{LOC}_{2}$ layer does not exist in Afrikaans. Another possibility is to posit that this layer is spelled out by a different element in Afrikaans. Since $\mathrm{LOC}_{2}$ in (2) is situated at the uppermost boundary of the genitive zone, it follows that an element which is typically associated with the dative zone could spell out this function. In the example in (ii) of this footnote, aan provides a reading that seems to correspond with $\mathrm{LOC}_{2}$ : it serves to express the idea that the ground has a twodimensional surface. Here, the meaning of aan contains the information "to/against (a surface/side)"; the sentence is ungrammatical with a ground such as those in (i) on the previous page.

(ii) (a) Dit plak aan die muur vas.

it sticks to the wall fast

"It is sticking to the wall"

(b) *Dit plak aan ver (vas).

it sticks to far fast

${ }^{6}$ Whether this repository is conceptualised as forming part of the conceptual systems of the mind is not clear. However, it is important to distinguish this notion from that of the lexicon proper which contains lexical items (i.e. complex bundles of conceptual, phonological and syntactic information).

${ }^{7}$ Caha $(2007,2009)$ gives an exposition of how the spellout of non-terminal nodes in NS allows the framework to account for what is achieved in Distributed Morphology (DM) with the concepts of 'pre-syntactic bundles' and 'zero-morphology' as well as the operations of fission and fusion. Caha provides extensive argumentation for the spellout of non-terminal nodes as theoretically simple and elegant in comparison to the equivalent devices incorporated in the DM framework. 
are subsequently inserted - is governed by (i) the superset principle, (ii) the elsewhere condition, and (iii) the anchor condition, as follows:

(4) The superset principle: A linguistic element qualifies for insertion iff it is specified for a superset of the features to be spelled out.

(Adapted from Caha 2007:5)

(5) The elsewhere condition: Let E1 and E2 be competing elements that have D1 and D2 as their respective domains of application. If D1 is a proper subset of D2, E1 blocks the application of E2 in D1.

(Adapted from Caha 2007:5)

(6) The anchor condition: A lexical item qualifies for insertion iff its lowest node is a match for a node in the syntactic structure. ${ }^{8}$

How the superset principle and the elsewhere condition apply to spellout is briefly discussed and illustrated in section 1.3. ${ }^{9}$

\subsection{Syncretism and accidental homophony}

When two or more grammatical functions are associated with the same form, the linguistic element capturing the two functions is said to be "syncretic" (Gvozdanovic 1991:135). Syncretism defies the expectation that there should be a one-to-one form-to-meaning relation between positions in a paradigm. Suppose, for example, that the nouns in a language inflect for four cases (nominative, accusative, genitive, dative) and two numbers (singular, plural); then we would expect all nouns to have 4x2 forms (Spencer 2003:252). A paradigm which conforms to this expectation is, according to Spencer, an "exhaustive paradigm". However, it seems that most paradigms actually contain fewer forms than the number of grammatical oppositions. When two grammatical oppositions are syncretic, it is possible to distinguish between them by comparison with other parts of the paradigm, i.e. parts where the grammatical oppositions are not syncretic (Gvozdanovic 1991:135). This property of inflectional paradigms renders them systematic and makes it possible to identify syncretic elements. An important conceptual distinction, therefore, is the one between syncretism and what is known as "accidental homophony".

According to Baerman, Brown and Corbett (2005:3), "we do not have the same expectations of consistency and completeness for derivational morphology as for inflection". It is widely accepted that syncretism, which could be described as "systematic homophony", is conceptually distinct from accidental homophony. Syncretism is (morpho-)syntactic in nature, whereas accidental homophony is (morpho-)phonological in nature (Baerman et al. 2005:9-10). Many researchers restrict inquiries on syncretism to the study of inflectional paradigms and are not concerned with derivation or lexical homophony. ${ }^{10}$

\footnotetext{
8 Abels and Muriungi (2008:720) describe the anchor condition as "the condition according to which the bottom of the spelled-out stretch must coincide with the bottom of the morpheme, effectively anchoring the spellout domain of a given morpheme at the bottom, [and which] ensures that there is a subset/superset relation between the different uses of a given morpheme". Due to spatial limitations, the theoretical validity of this condition is not argued in this paper. Cf. also argumentations by Caha (2009) and Pantcheva $(2009 ; 2010)$.

9 Cf. Pretorius and Oosthuizen (2012b) for a more detailed exposition of the NS framework.

${ }^{10}$ Cf. e.g. Carstairs-McCarthy (1991), Blevins (1995), Stump (2001), Müller (2004) and Baerman et al. (2005).
} 


\subsection{Underspecification and overspecification}

Underspecification concerns the relation of grammatical function to form. Across approaches, most accounts of syncretism rely on some notion of 'underspecification'. Typically, a syncretic element (referred to as an "elsewhere" form in the context of under-/overspecification) is conceived as being specified for fewer features than any of the given positions in the paradigm that it spells out. Crucially, the elsewhere form may only be inserted in the absence of a more specific element. Contained in the notion of 'underspecification' are two assumptions captured by the subset principle and the elsewhere condition (the latter is repeated in (8) for ease of reference):

(7) The subset principle: A linguistic element qualifies for insertion iff it is specified for a subset of the features to be spelled out.

(8) The elsewhere condition: Let E1 and E2 be competing elements that have D1 and D2 as their respective domains of application. If D1 is a proper subset of D2, E1 blocks the application of E2 in D1.

(Adapted from Caha 2007:5)

The subset principle is used to select competitors from a larger set of qualifying linguistic elements; the elsewhere condition is then used to choose "a winner" from the competitors, that is, the element containing the least superfluous information.

Distributed Morphology (DM), which incorporates the notion of 'underspecification', is arguably the framework most closely related to NS as it also approaches syntactic analysis primarily from below the level of the word. ${ }^{11}$ Unlike DM, however, NS incorporates the notion of 'overspecification', which requires the elsewhere form to be more specific than the other elements in the paradigm. When the elsewhere form is inserted, the "unused" features are said to be "underassociated" (or "ignored"). In the event of two elsewhere forms competing for insertion, the elsewhere condition still applies; that is, the form containing the fewest superfluous features wins and is inserted. Overspecification requires the subset principle to be adjusted, resulting in the superset principle (repeated in (9) for ease of reference):

(9) The superset principle: a linguistic element qualifies for insertion iff it is specified for a superset of the features to be spelled out.

(Adapted from Caha 2007:5)

Caha $(2007,2009)$ argues for the theoretical superiority of overspecification. He derives from a number of inflectional paradigms the following abstract pattern for syncretism: ${ }^{12}$

\begin{tabular}{llll}
\hline & I & II & III \\
\hline $\mathbf{X}$ & D & A & B \\
$\mathbf{X Y}$ & D & D & C \\
$\mathbf{X Y Z}$ & D & D & D \\
\hline
\end{tabular}

\footnotetext{
${ }^{11}$ Cf. Halle and Marantz (1994:276) for a DM perspective on underspecification and the subset principle.

12 These paradigms include English verbal participles and cross-linguistic case paradigms.
} 
Underspecification predicts the incorrect empirical results with regards to the pattern for syncretism in (10), whereas overspecification appears to make the correct predictions. On the assumption that the elsewhere form, D, is underspecified and inserted according to the subset principle, it can be inferred that each linguistic element is specified as follows (the context in which a given linguistic element may appear is given, in (11), as / II, / III):

$$
\begin{aligned}
& / \mathrm{D} / \rightarrow[\mathrm{X}] \\
& / \mathrm{A} / \rightarrow[\mathrm{X}] / \mathrm{II} \\
& / \mathrm{B} / \rightarrow[\mathrm{X}] / \mathrm{III} \\
& / \mathrm{C} / \rightarrow[\mathrm{X}, \mathrm{Y}] / \mathrm{III}
\end{aligned}
$$

Notice that A, which is specified for a subset of [X, Y] and [X, Y, Z] in context II, ought to be inserted into all the positions of context II. Likewise, $\mathrm{C}$, which is a subset of [X, Y] and [X, Y, Z] in context III, ought to be inserted into D's position in context III, which incorrectly predicts the following paradigm:

\begin{tabular}{llll}
\hline & I & II & III \\
\hline $\mathbf{X}$ & D & A & B \\
$\mathbf{X Y}$ & D & A & C \\
$\mathbf{X Y Z}$ & D & A & C \\
\hline
\end{tabular}

Overspecification, by contrast, would require the items in paradigm (10) to be specified as follows:

$$
\begin{aligned}
/ \mathrm{D} / & \rightarrow[\mathrm{X}, \mathrm{Y}, \mathrm{Z}] \\
/ \mathrm{A} / & \rightarrow[\mathrm{X}] / \mathrm{II} \\
/ \mathrm{B} / & \rightarrow[\mathrm{X}] / \mathrm{III} \\
/ \mathrm{C} / & \rightarrow[\mathrm{X}, \mathrm{Y}] / \mathrm{III}
\end{aligned}
$$

Assuming then, by virtue of the superset principle, that an item can only be inserted into a node or position in a paradigm if it is specified for a superset of the features contained in the node, the specifications in (13) yield the correct empirical results and produce the desired distribution in paradigm (10).

The NS assumption regarding the syncretism shown by an element such as van is that the lexical item is encoded with a fully specified structure (i.e. one containing all the nodes in the decomposition in (3)) as illustrated in (14a). With the structure represented in (14a), van qualifies for insertion into any of the structures represented in (14b-d): When van is inserted into (14b), it corresponds with a locative interpretation and the nodes POS and PART in the lexical entry are underassociated; when van is inserted into (14c), it corresponds with a possessive interpretation and the node PART is underassociated; finally, when van is inserted into (14d), it is a perfect match and corresponds with a partitive interpretation. Importantly, the anchor condition would prohibit any lexical entry which does not contain the $\mathrm{LOC}_{1}$ node from being inserted into any of the structures in (14b-d) since such an entry could not be matched against the lowest node in the syntactic structure. 
(14) (a) Lexical entry for van:

$$
\text { van } \leftrightarrow</ \mathrm{f} \Lambda \mathrm{n} /, \mathrm{FROM} / \mathrm{OF},
$$

Structure built by syntax, corresponding with:

(b) a locative interpretation:<smiles>CCC(=O)O</smiles>

(d) a partitive interpretation:

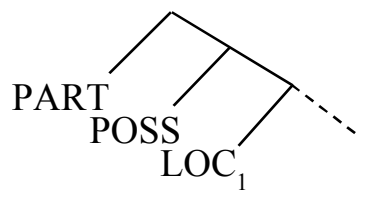

(c) a possessive interpretation:

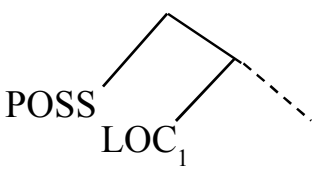

In the course of the analysis of van in section 3, modifications will be made to the internal structure of van as it is represented in (14). Again, it is important to note that this inquiry focuses on the partitive function of van and that a complete structural analysis of this $\mathrm{P}$ element and all its functions will not be attempted here.

\section{Three Afrikaans partitive constructions}

According to Hoeksema (1996:1-2), the partitive relation denotes the intersection of two sets one set denoting "the whole", which can be referred to as "the quantified set", and one set denoting "the part", which can be referred to as "the quantifying set". ${ }^{13}$ The (semantic) partitive relation shows some dissociation with any corresponding syntactic construction. Three constructions associated with the partitive relation, namely the "typical partitive", "pseudopartitive" and "made of"-partitive, are briefly described in this section.

In English, the typical partitive construction consists of a quantified element (usually a noun) and a quantifying element (usually a quantifier) with of mediating between them, as in (15). The Afrikaans equivalents with van are given in (16):

(a)

(i) Some of the senators

(b)

(ii) Many of his friends

(i) Most of the city

(ii) Part of him

(Hoeksema 1996:1-2)

\footnotetext{
${ }^{13}$ On the one hand, the term "partitive" refers to the expression of the "part of"-relation (i.e. semantic information); on the other hand, it refers to a type of syntactic construction and often also to a (morphological) case. "Partitive" in this paper is used mainly in reference to the expression of the semantic "part of"-relation.
} 
(16) (a) (i) (Party) van die senatore

some of the senators

(ii) Baie van sy vriende

many of his friends

(b) (i) (Die) meeste van die stad

the most of the city

(ii) ('n) Deel van hom

a part of him

As the term suggests, the "made of"-partitive is associated with a constitutive interpretation. Importantly, and in contrast with the pseudo-partitive construction, van does not render this type of construction ungrammatical - van is, in fact, obligatory in "made of"-partitive constructions and cannot be omitted. Consider the examples in (17):
(a) 'n Huis *(van) hout
a house of wood
"A house made of wood"
(b) 'n Man *(van) strooi
a man of straw
"A man made of straw"

Corver (2004) employs the term "pseudo-partitive" to refer to partitive constructions that take a noun as the quantifying element. The examples with of in (18) illustrate the pseudo-partitive in English. Note, however, that the pseudo-partitive in Afrikaans cannot be spelled out with van - the Afrikaans equivalents of (18), given in (19), are ungrammatical with van. ${ }^{14}$
(a) A bunch of flowers
(b) A glass of water

Caha $(2009: 111)$

(a) 'n Bos (*van) blomme

a bunch of flowers

(b) 'n Glas (*van) water

a glass of water

\footnotetext{
${ }^{14}$ Corver (1998) proposes an analysis of pseudo-partitive constructions which establishes an NP-internal subjectpredicate relation between the quantifying element (bos and glas in (19)) and the quantified element (blomme and water in (19)). The $\mathrm{P}$ element is analysed as a nominal copula, manifesting as a result of predicate inversion, and spells out a functional head F (Corver 2004:38-42; cf. also Den Dikken 2006). In Afrikaans constructions like (19), the appearance of van is blocked due to the fact that the quantifying element (bos and glas in (19)) has moved into the position under $\mathrm{F}$, blocking insertion of van at PF.

Den Dikken (2006) provides a syntactic analysis of the relation between subjects and their predicates. His study highlights the significance of "relators" in various types of predication, namely on a phrasal as well as a clausal level, and involving various grammatical constructions and categories. In his analysis, relators do not form a new grammatical category, but constitute a class of functional elements belonging to existing grammatical categories. Relators do not receive the same spellout across languages and are often not realised phonologically by separate linguistic elements. In Rotuma, for example, the element ne mediates between subject and predicate on both phrasal and clausal levels, between elements of various categories; in itself, however, ne carries no inherent meaning and it appears as though its sole function is to establish a relation between the so-called subject and predicate.
} 
The fact that van cannot spell out the very same functions that are associated with the genitive element of in English relates to the partitioning of structure in different languages: the very same (perhaps universal) structure is spelled out utilising elements that are specified for different sections of that structure. ${ }^{15}$ There are, however, instances in which van may spell out a pseudo-partitive. Consider the behaviour of van in the following pseudo-partitive constructions: ${ }^{16}$
(a) 'n sny (*van) koek a slice of cake
(b) 'n sny *(van) die koek a slice of the cake
(c) 'n sny *(van) 'n koek a slice of a cake
(d) drie snye *(van) elke koek three slices of every cake
(e) drie snye (*van) koek three slices of cake

On the one hand, van is obligatory whenever the quantified DP koek is modified by an (in)definite article or quantifier ${ }^{17}$ (such DPs are henceforth referred to as "specific DPs"); on the other hand, van is ungrammatical in the absence of an article or quantifier modifying the DP koek (such DPs are henceforth referred to as "generic DPs"). The example in (20e) shows that van is ungrammatical, even when the quantifying QP drie snye is specific, if the quantified DP koek is generic. These observations of the data in (20) can be summarised as follows: the P element van is obligatory when the quantified DP is specific; conversely, van renders the sentence ungrammatical when the quantified DP is generic. We return to these observations in section 3 .

\section{Towards an analysis of van}

\section{1 *(van)/(*van) in the pseudo-partitive}

It should be clear from the discussion above that there is no homogenous construction expressing partitive relations in Afrikaans. This section aims to provide a structural analysis that can account for the seemingly irregular behaviour of van in spelling out the partitive relation, especially in the pseudo-partitive construction. The section begins with an analysis of the pseudo-partitive construction which is subsequently extended to the other partitive constructions.

\footnotetext{
${ }^{15}$ Cf. Pantcheva (2011:193-217) for a discussion on the partitioning of structure.

${ }^{16}$ Note that modification by an adjective has no effect on the (un-)grammaticality of (18-19) with van:

(i) 'n Bos (*van) rooi blomme/'n Rooi bos (*van) blomme a bunch of red flowers / a red bunch of flowers

(ii) 'n Glas (*van) koue water / 'n Koue glas (*van) water a glass of cold water / a cold glass of water

${ }^{17} \mathrm{Cf}$. also Ponelis (1979:153-155) with regards to the effect of quantifiers (and numerals) modifying the quantified part of pseudo-partitive constructions.
} 
The structural analysis is conducted within the NS framework; however, arguments by Den Dikken (1998, 2006), Corver (1998, 2003, 2004) and Oosthuizen (2013) for the internal structure of nominal expressions are taken as a point of departure. Specifically, and with reference to Oosthuizen (2013), the analysis presented here can be seen as equivalent to a nominal shell analysis in which the partitive complex represents a "little $n$ ", establishing a partitive relation between the quantified and the quantifying DPs. The quantified element will be referred to as $\mathrm{DP}_{1}$ and the quantifying element as $\mathrm{DP}_{2}$. The partitive complex takes $\mathrm{DP}_{1}$ as its complement and $\mathrm{DP}_{2}$ as its specifier. Whether it is overtly realised or not, the partitive complex is always comprised of the same structural sequence, namely a modified version of Caha's (2009) decomposition of the genitive zone as given in (3). The structural arrangement described here is represented in (21).

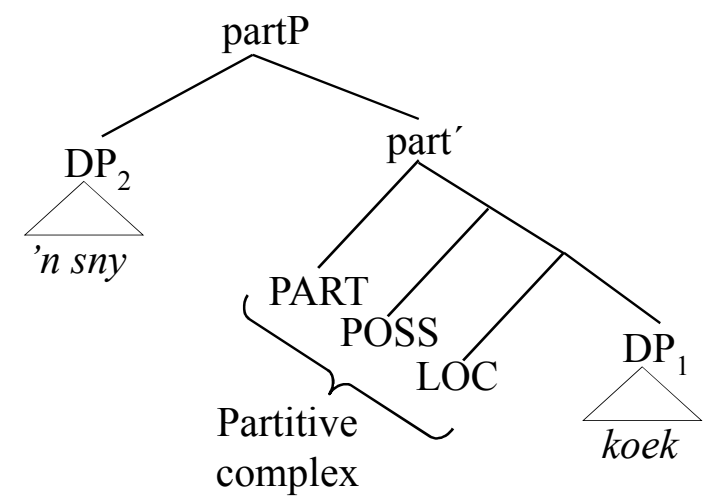

In order to accommodate the observations of the pseudo-partitive examples in (20) in the structure in (21), an additional node, Specific (SPF), is posited in the uppermost layer of a specific DP/QP; this node is absent in generic DPs. ${ }^{18}$ The lexical entry for the P element van is then encoded with the structure in $(22):{ }^{19}$

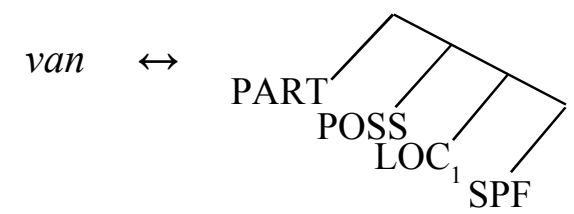

\footnotetext{
${ }^{18}$ An anonymous reviewer remarked that the presence of an overt D denotes specificity and that any DP is inherently going to have the feature SPF. This raised the question as to whether SPFP is not simply the DP, and whether a generic nominal expression is not just an NP without a DP. It is, however, assumed here that every NP is headed by a DP, whether the D is covert or overt. The reason for this assumption is that "bare" nominal expressions can sometimes have a specific reading (cf. e.g. the data in (28) and (29) in which "bare" nominals are given specific interpretations in the context of possessive or locative expressions). This "specific" reading is taken to be contributed by the SPF node of a covert D, which is present but is not realised by a separate lexical item (although it is argued that SPF received expression through van). It thus seems to be the case that (non-)specificity cannot be reduced to the presence or absence of an overt D.

${ }^{19}$ Other functions spelled out by van would require other additional nodes to be introduced above PART. One such node is the verbal syntactico-semantic feature [Res] (cf. Ramchand 2008), which could perhaps account for the difference in meaning between the "made of"-partitive and the typical partitive. In addition, the presence of such a verbal feature in the structural decomposition of van could play a role in accounting for the obligatory presence of van in fixed verbal constructions with the verb hou.
} 
According to the anchor condition, van cannot be inserted into a structure unless the lowest node in its lexical entry matches a node in the syntactic structure. This means that the lexical item van cannot be inserted when there is no SPF node in the structure generated by syntax. When SPF is present in the uppermost layer of a specific DP/QP, then the lexical item van is matched against this feature of the DP/QP domain and the rest of the partitive complex's sequence. In the absence of SPF in the structure of a generic DP, the lowest feature in the lexical entry of van cannot be matched against the structure and van cannot be inserted. By extension, SPF is represented in the structures of all specific DPs/QPs, even when they do not form the complement of a partitive complex. In such cases, SPF is spelled out by the relevant lexical entries of the specific DP/QP. When van spells out SPF in a partitive construction, the SPF node on the lexical entry of the relevant $\mathrm{D} / \mathrm{Q}$ is underassociated, which is permissible because it is the highest feature in the structure encoding D/Q. The P element van essentially "takes over" the SPF node, which is normally spelled out by $\mathrm{D} / \mathrm{Q}$. The structures corresponding with utterances such as (20a) and (20b) are therefore represented in (23a) and (23b) respectively. ${ }^{20}$

(a)

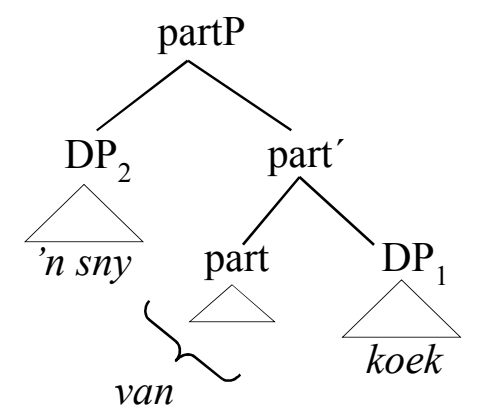

(b)

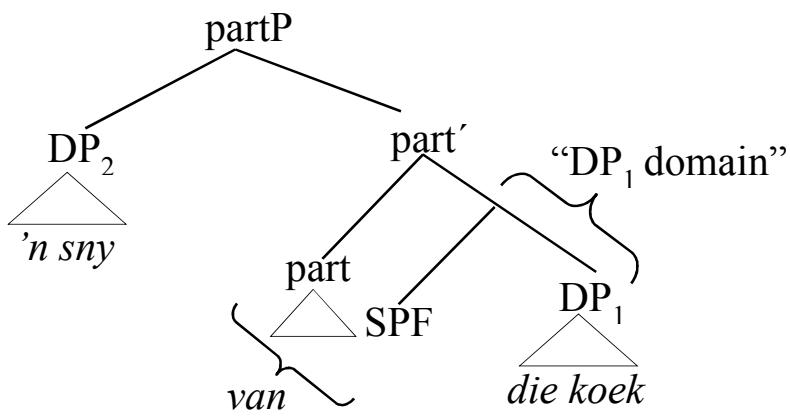

The observations in this section concerning the presence/absence of van in pseudo-partitive constructions in Afrikaans do not hold for English. In English, of is spelled out regardless of whether its complement is specific or generic. This indicates that the syntactic structure representing the pseudo-partitive construction is partitioned differently in the lexical items of Afrikaans and English. Specifically, the lexical entry of is not encoded with SPF, allowing it to be inserted to spell out a partitive complex sequence which takes either a specific or generic $\mathrm{DP} / \mathrm{QP}$ as a complement.

\subsection{Extending the analysis}

The analysis presented in the previous section can plausibly be applied to other partitive constructions as well. Consider first how it would be extended to the typical partitive

\footnotetext{
${ }^{20}$ An anonymous reviewer raised the question whether, since any specific DP necessarily always has an SPF feature, it does not predict that an ordinary determiner may be lexicalised in addition to van. In other words, what would prevent an ungrammatical expression like van die man lees, where van is over-generated in order to represent specificity? This is indeed a valid question, since van would be a candidate for insertion into an expression like die man lees, where the uppermost node of die is presumed to be SPF. It seems, however, that the elsewhere condition would rule out the possibility of SPF receiving separate spellout in such an expression since there would be too many superfluous nodes in the lexical entry of van and the SPF node could be more economically spelled out by the D itself. Van is only inserted when other nodes (that belong to the "true" $\mathrm{P}$ domain) cannot be spelled out by the determiner, in which case van (or perhaps another P element) "bullies" the D into "handing over" the SPF node so that the nodes in the "true" P domain can be spelled out. The case of a P element spelling out the SPF node is essentially, then, a "last resort" before a derivation crash.
} 
construction of the type shown in (24). Note that, consistent with the observations of the pseudo-partitive construction in section 2 , when $\mathrm{DP}_{1}$ is specific, van is obligatory as shown in (24a); when $\mathrm{DP}_{1}$ is generic, the use of van results in ungrammaticality as shown in (24b).
(a) (Party) van die senatore
(Some) of the senators
(b) Party (*van) senatore
Some of senators

The fact that party in (24a) can be omitted serves as a further indication that the spellout of van is related to the presence/absence of SPF on $\mathrm{DP}_{1}$, die senatore, as opposed to some property of the quantifying QP, party. Moreover, the fact that neither the meaning nor the grammaticality of $(24 a)$ is affected by the omission of party suggests that the essential partitive structure is "complete" once the partitive complex merges with its complement $\mathrm{DP}_{1}$, die senatore. Structurally, $(24 a-b)$ can be represented as in $(25 a-b)$ respectively.

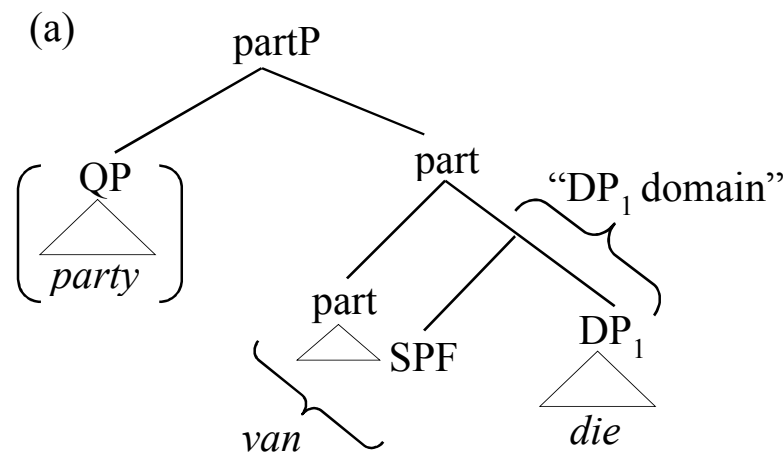

(b)

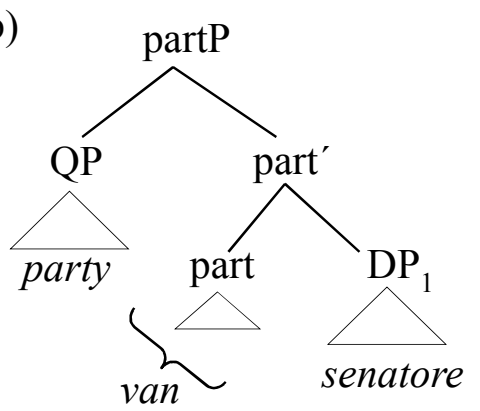

The analysis can also be extended to "made of"-partitives, of the type in (26):
(a) 'n huis van hout a house of wood
(b) 'n huis van daardie hout
(c) (?) huise van hout houses of wood

Van is always compulsory with this type of partitive construction. Given the line of argumentation followed in the analysis thus far, this would suggest that the complement of the partitive complex must always be specific. On the one hand, the example in (26b) illustrates that the specificity of the DP (daardie) hout does not have an effect on the grammaticality of the "made of"-partitive construction as it is generic in (26a) and specific in (26b) and has no effect on the grammaticality. The expression in (26c), on the other hand, is only good when huise is given a specific interpretation; a generic interpretation would render the utterance unacceptable. In other words, (26c) will normally be interpreted as "a certain set of houses that are made of wood, falling within a generic set of houses that are not necessarily made of wood". Therefore, it is proposed that 'n huis/ huise in (26) forms the complement of the partitive complex, contrary to the expectation created by the surface word order in which the $\mathrm{DP}_{1}$ and $\mathrm{DP}_{2}$ have become inverted. 
(a)

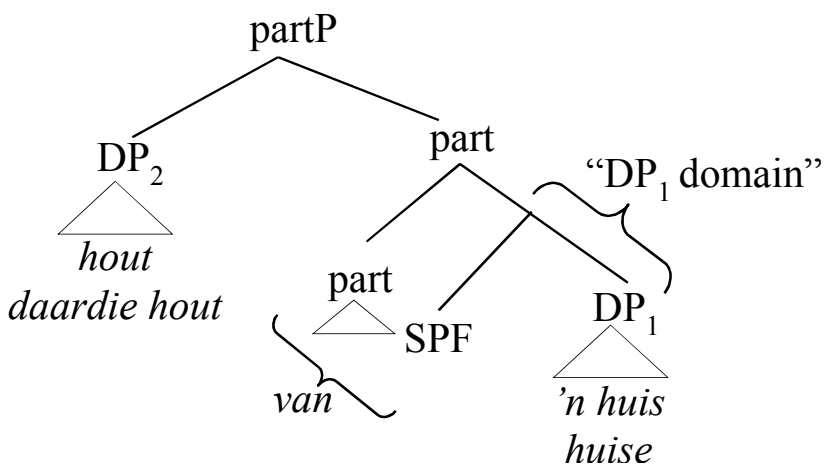

Positing an additional node SPF at the bottom of the structural sequence encoded on the lexical entry of van also has implications for the other functions that van spells out. Specifically, it predicts that van can never take a generic DP/QP complement, even in spatial, possessive, verbal and QBNP expressions. Although a systematic investigation is required in order to draw any conclusions, the exploratory discussion below seems to suggest that this prediction holds true.

Regarding van in locative expressions, this prediction seems to be accurate: DPs corresponding with a one-dimensional point in space - such as hier ("here"), ver ("far"), daar ("there"), naby ("near") - are specific even though they are deictic. Non-deictic one-dimensional points in space, such as place names, are also specific:

'n Man van hier/ver/daar/naby/ Stellenbosch

a man from here/far/there/nearby/Stellenbosch

Ponelis (1979:151-152) notes that possessive van-constructions are most acceptable when the DP containing the possessor is larger than the DP containing the possessee. Consider the following examples in this regard: ${ }^{21}$

(29) (a) Kamers van studente wat hou van kuier rooms of students that like of party "Rooms of students that like to party"

(b) Die kamers van die studente wat hou van kuier The rooms of the students that like of party "The rooms of the students that like to party"

(c) Die kamers van studente wat hou van kuier the rooms of students that like of party "The rooms of students that like to party"

(d) ?Kamers van die studente wat hou van kuier rooms of the students that like of party "Rooms of the students that like to party"

In (29a) both the possessee and possessor DPs appear to be generic; in (29b) both the possessee and possessor DPs appear to be specific; in (29c) the possessee DP die kamers appears to be

\footnotetext{
${ }^{21}$ Note that the second instance of van which appears in each example in (29) can be described as a "verbal particle" without which the verb hou ("like") cannot occur.
} 
specific and the possessor DP containing studente generic; and finally, in (29d) the possessee DP appears to be generic and the possessor DP specific. Most speakers seem to find (29a-c) equally acceptable and (29d) only slightly less acceptable.

It is not immediately clear that the analysis proposed here can be extended to the examples in (29) as the presence of van does not seem to be sensitive to whether its complement is generic or specific. A possible solution to this problem could come from the following observation: the possessee of any possessive construction must have a specific interpretation. In other words, the possessee cannot be given a generic interpretation because any set that is "possessed", by default, constitutes a subset of a larger set comprising both the possessed and non-possessed entities. To make this idea concrete, consider kamers in (29a and d). In both cases kamers appears to be generic, i.e. referring to any and all rooms. However, in the context of a possessive construction in which kamers refers to rooms that are "possessed" by students, even if studente is generic, referring to any and all students, kamers can only refer to rooms that are possessed by students. In other words, kamers refers to a smaller subset of all rooms, namely rooms that are possessed by students.

Following from this argument, it is proposed that the complement of the possessive complex spelled out by van is the DP denoting the possessee and not the possessor. It is then correctly predicted that the derivation will crash whenever the possessive complex, which must eventually be spelled out by van, is merged with a DP not containing SPF. If the structure gets built up to the PART layer, structures containing SPF will be spelled out by van and structures not containing SPF will be spelled out without van.

\subsection{Limitations and suggestions for further research}

An obvious limitation of this study is that it does not include a theory about how spellout-driven movement in NS applies to the underlying structural representations in order to derive the correct surface word orders. Briefly, when the lexicon proper is searched for lexical items matching the structure produced in the syntax, movement takes place to create an acceptable configuration if no matching items are found. ${ }^{22}$ The spellout of non-terminal nodes is crucial in this theory of movement because a lexical entry, which includes a non-terminal node, can "trigger" so-called "evacuation movement" of all the nodes below it if it includes a non-terminal (phrasal) node which stipulates no additional nodes. ${ }^{23}$ Accordingly, for base-configurations such as the "made of"-partitive, where the DPs need to invert to attain the correct surface word order, a stipulation in the lexical entry of van could trigger this movement. The (partial) lexical entry for van is repeated in (30) from section 3.1:

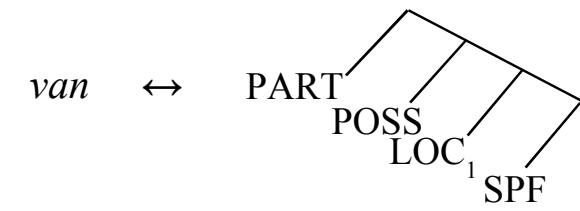

\footnotetext{
${ }^{22}$ Cf. e.g. Caha (2010) and Pantcheva (2011) for fuller characterisations of spellout-driven movement in NS.

${ }^{23}$ Cf. e.g. Caha (2009) for an explanation of "evacuation movement".
} 
Note that no additional nodes are encoded below the phrasal node dominating SPF. According to the theory of spellout-driven movement, in order for van to be inserted into a syntactic configuration, the nodes in the configuration that form the complement of SPF must be moved out for the configuration to be a match for the lexical entry. This seems promising in the case of "made of"-partitives, in which movement of the DP complement of SPF must occur in order to generate the correct surface word order. However, with typical partitive constructions and pseudo-partitive constructions this movement does not seem to occur as the DPs do not invert. Yet, if the lexical entry of van stipulates that evacuation movement is required, how can it be accounted for that $\mathrm{DP}_{1}$ sometimes moves and sometimes does not? Furthermore, the fact that $\mathrm{DP}_{1}$ does seem subject to movement in the derivation of "made of"-partitives does not make deriving the surface word order with spellout-driven movement unproblematic: after the first movement operation described here, the linear word order stands at $\mathrm{DP}_{2}-\mathrm{DP}_{1}$-van, whereas the correct order is $\mathrm{DP}_{1}$-van- $\mathrm{DP}_{2}$. One could postulate that the entry of the "lowest" item in $\mathrm{DP}_{2}$ also requires evacuation movement in order to be spelled out, but then it is not clear why the same item in $\mathrm{DP}_{1}$ does not trigger movement.

Obviously, it is necessary for a systematic analysis to be developed of all the other functions which van can spell out in order to provide a full account of this item's internal structure. As a starting point, it seems plausible that the internal structure of van incorporates some or other verbal node above PART. This could aid in accounting for the difference in meaning between the "made of"-partitive on the one hand, and the typical and pseudo-partitives on the other hand. In turn, this could serve as a basis for an analysis of van when it acts as a verbal particle in fixed constructions, such as (1g), repeated in (31). Specifically, this could involve a verbal head, such as Ramchand's (2008) [Res]-node entering the decomposition above PART. ${ }^{24}$

Sy hou van klein kinders

she likes of small children

"She likes small children"

In this type of construction, it is likely that van serves to mark the object argument as the theme. Pantcheva (2011) provides an analysis for fixed constructions such as this (cf. fn. 15 in this regard). On her analysis, the $\mathrm{P}$ element spells out a part of the verbal structure; the verb hou is therefore "deficient" in the sense that it is dependent on the P element in order to be spelled out at all.

\section{Conclusion}

In this paper, syncretism, as an empirical phenomenon pervasive in natural language, was investigated from a theoretical point of view. Syncretism is not a phenomenon that has received much attention from within generative studies; NS represents the minimalist framework which has devoted the most systematic attention to accounting for it. Three Afrikaans partitive constructions which utilise the $\mathrm{P}$ element van were described. Following observations of the seemingly irregular behaviour of van with the pseudo-partitive construction, and taking Caha's (2009) decomposition of the genitive zone as a point of departure, a tentative structural analysis

\footnotetext{
${ }^{24}$ Cf. Ramchand (2008) on the decomposition of verb event structure and for an introduction to the verbal syntactico-semantic heads [Init(iation)], [Proc(ess)] and [Res(ult)]. Cf. also Pretorius and Oosthuizen (2012a) for an introduction to these theoretical notions.
} 
of van was proposed. In particular, the addition of the functional head SPF beneath Caha's LOC 1 head was argued for. Essentially, this predicts that van can only merge with a complement that is specific (as opposed to generic). This prediction seems to hold for other partitive constructions, as well as for constructions in which van spells out other (non-partitive) functions.

The analysis proposed in this paper not only sheds light on the internal structure of $\mathrm{P}$ elements that are associated with the genitive zone, but also takes into consideration how van interacts with other elements in the construction on a word level, a dimension that is lacking from most current NS analyses.

\section{References}

Abels, K. and P. Muriungi. 2008. The focus marker in Kîttharaka. Lingua 118(5): 687-731.

Baerman, M., D. Brown and G.G. Corbett. 2005. The syntax-morphology interface: A study in syncretism. Cambridge: Cambridge University Press.

Blevins, J. 1995. Syncretism and paradigmatic opposition. Linguistics and Philosophy 18(2): $113-152$.

Brown, D. and A. Hippisley. 2012. Network morphology: A defaults-based theory of word structure. Cambridge: Cambridge University Press.

Caha, P. 2007. The superset principle. Ms. University of Tromsø.

Caha, P. 2009. The nanosyntax of case. PhD dissertation. University of Tromsø.

Caha, P. 2010. The parameters of case marking and spell-out driven movement. In J. Van Craenenbroeck (ed.) Linguistic variation yearbook 2010. Amsterdam/Philadelphia: John Benjamins. pp. 32-77.

Carstairs-McCarthy, A. 1991. Inflectional paradigms: two questions with one answer. In F. Plank (ed.) Paradigms: the economy of inflection. Berlin: Mouton de Gruyter. pp. 213-254.

Corver, N. 1998. Predicate Movement in Pseudopartitive Constructions. In A. Alexiadou and C. Wilder (eds.) Possessors, Predicates and Movement in the Determiner Phrase. Amsterdam/Philadelphia: John Benjamins. pp. 215-258.

Corver, N., 2003. On three types of movement within the Dutch nominal domain. In M. Coene and Y. D'Hulst (eds.) From NP to DP: the syntax and semantics of noun phrases. Amsterdam/ Philadelphia: John Benjamins. pp. 297-328.

Corver, N. 2004. Emphatic forms and displacement in Dutch. In A. Breitbarth and H. Van Riemsdijk (eds.) Triggers. Berlin: Mouton de Gruyter. pp. 135-171. 
Den Dikken, M. 1998. Predicate inversion in DP. In A. Alexiadou and C. Wilder (eds.) Possessor, predicates and movement in the determiner phrase. Amsterdam/ Philadelphia: John Benjamins. pp. 177-214.

Den Dikken, M. 2006. Relators and linkers: The syntax of predication, predicate inversion, and copulas. Cambridge, Ma.: MIT Press.

Gazdar, G., E. Klein, G. Pullum and I.A. Sag. 1985. Generalized phrase structure grammar. Cambridge, Ma.: Harvard University Press.

Gvozdanovic, J. 1991. Syncretism and the paradigmatic patterning of grammatical meaning. In F. Plank (ed.) Paradigms: the economy of inflection. Berlin: Mouton de Gruyter. pp. 133-160.

Halle, M. and A. Marantz. 1994. Some key features of distributed morphology. MIT Working Papers in Linguistics 21: 275-288.

Hoeksema, J. 1996. Introduction. In J. Hoeksema (ed.) Partitives. Berlin and New York: Mouton de Gruyter. pp. 1-24.

Kaplan, R.M. and J. Bresnan. 1982. Lexical-functional grammar: A formal system for grammatical representation. In J. Bresnan (ed.) The mental representation of grammatical relations. Cambridge, Ma.: MIT Press. pp. 173-281.

Kay, M. 1979. Functional Grammar. In Proceedings of the Fifth Annual Meeting of the Berkeley Linguistics Society. The University of California at Berkeley: Berkeley Linguistics Society.

Müller, G. 2004. On decomposing inflection class features. In G. Müller, L. Gunke and G. Zifonun (eds.) Explorations in nominal inflection. Berlin: Mouton de Gruyter. pp. 189-128.

Oosthuizen, J. 2013. Obligatory reflexivity in Afrikaans. PhD dissertation. Stellenbosch University.

Pantcheva, M.B. 2009. Directional expressions cross-linguistically: Nanosyntax and lexicalization. Nordlyd 36(1): 7-39.

Pantcheva, M.B. 2010. The syntactic structure of locations, goals, and sources. Linguistics 48(5):1043-1081.

Pantcheva, M.B. 2011. Decomposing path: The nanosyntax of directional expressions. PhD dissertation.University of Tromsø.

Pollard, C. and I.A. Sag. 1994. Head-driven phrase structure grammar. Chicago: University of Chicago Press.

Ponelis, F.A. 1979. Afrikaanse sintaksis. Pretoria: J.L. Van Schaik.

Pretorius, E. and J. Oosthuizen. 2012a. A nanosyntactic analysis of Afrikaans passive participles. Southern African Linguistics and Applied Language Studies 30(4): 449-467. 
Pretorius, E. and J. Oosthuizen. 2012b. Nanosyntax: A fresh approach to syntactic analysis. Southern African Linguistics and Applied Language Studies 30(4): 433-447.

Ramchand, G. 2008. Verb meaning and the lexicon. Cambridge: Cambridge University Press.

Sadler, L. and R. Nordlinger. 2006. Case stacking in realizational morphology. Linguistics 44(3): 459-487.

Spencer, A. 2003. Periphrastic paradigms in Bulgarian. In U. Junghanns and L. Szucsich (eds.) Syntactic structures and morphological information. Berlin and New York: Mouton de Gruyter. pp. 249-282.

Starke, M. 2009. Nanosyntax: A short primer to a new approach to language. Nordlyd 36(1): $1-6$.

Stump, G.T. 1993. On rules of referral. Language 69(3): 449-479.

Stump, G.T. 2001. Inflectional morphology: A theory of paradigm structure. Cambridge: Cambridge University Press. 